\title{
FORMING THE COMPOSITION OF UNDERGROUND COAL GASIFICATION PRODUCTS IN THE SIMULATION OF VARIOUS HEAT AND MASS TRANSFER CONDITIONS IN THE COAL SEAM
}

\author{
A.S. Masanik ${ }^{1}, A$. N. Subbotin ${ }^{1, *}$, and A.S. Tarasanov ${ }^{1}$ \\ ${ }^{1}$ National research Tomsk Polytechnic University, 634050 Tomsk, Russia
}

\begin{abstract}
The mathematical model describing the heat and mass transfer processes in underground coal gasification is proposed. Numerical studies have allowed to determine the composition of gases depending on the temperature, pressure products of gasification, and the composition of the heated oxidant injected. Relations the composition of the concentration of combustible gas component of the oxidant injected: dry air, a mixture of oxygen, nitrogen and water vapor in different proportions were prepared. It is found that, depending on the oxygen content in the oxidizer lowtemperature gasification mode is implemented (up to $15 \%$ ). At higher values of the oxygen concentration in the oxidizer the high-temperature mode is realized, in which the fuel gas output increases significantly.
\end{abstract}

\section{Introduction}

Coal - a mineral resource, which is a unique material. A wide range of different products prepared on the basis thereof. Besides coal is one of the basic elements of modern fuel and energy balance in the world. Many countries are now actively developing modern coal deep processing technology to reduce the dependence of the production of chemical products from imports of oil and natural gas [1]. Look for new solutions to chemical and energy problems, natural resource extraction issues [2].

At present, almost all the major coal producing countries of the world are showing great interest in the underground coal gasification technology. It should be noted that the intensive research work and practical nature are underway in China, the US and many other countries [3]. Gasification is a low-temperature or high-temperature processes, which occur in the interaction of the organic mass of solid or liquid fuel or products of their thermal processing with oxygen, carbon dioxide, air, steam, or mixtures thereof. As a result of these processes is an organic part of the processed fuel turns into a combustible gas. [4]For gasification as feedstock, generally use peat, oil shale, lignite or stone. Typically, the oxidizing agent (gasifying agent) is air, oxygen or steam.

* Corresponding author: subbot@,tpu.ru 
The aim of this study is a numerical analysis of the conditions for the implementation of the underground coal gasification process, and analyzing the output composition of the synthesis gas depending on conditions, under which the gasification of the coal seam is carried out.

\section{Physical formulation of the problem}

Considered the most simple and quite typical diagram of underground coal gasification. The coal seam is drilled into which is inserted a pipe. Inside this pipe is placed a pipe of smaller diameter, with the extension and perforated holes at the bottom of the base. On the inside of the pipe in the coal seam is injected heated to a certain temperature, air or steamair mixture. Over time the coal seam warms up and it will start the process of pyrolysis further can be an ignition of coal. Through the holes on the side surface of the outer tube, the products of pyrolysis and combustion penetrate into the outer pipe and moved from the coal seam to the surface.

Changing characteristics of the supplied vapor oxidant, will get different gas composition at the outlet. Will conduct the study, how it will change the composition of the synthesis gas when changing the conditions of flow of oxidant and thermophysical properties.

For typical coals when they are heating, depending on temperature, can occur quite a number of reactions [3]. In the present work, it was assumed that the analyzed process is accompanied by gasification reactions [5].

\section{Numerical results of mathematical modeling}

A mathematical model describing the processes that occur during the gasification of the coal seam is shown in [5]. For the numerical solution of the boundary value problem given in [5] used the method of making and difference scheme [6]. All gasified fuel characteristics were calculated: temperature distribution in the coal seam, field of velocity of filtration and pressure, and the volume fraction of condensed gaseous pyrolysis products, the moisture concentration of the gaseous pyrolysis products. [6]. For the numerical calculations, some positive pressure was set at the entrance $\Delta \mathrm{P}=\mathrm{P}_{0}-\mathrm{P}_{\mathrm{H}}$, the moisture content of the coal seam $\mathrm{W}$, the mass concentration of oxygen and water vapor are ranged. From these numerical results imply that warmed area formed in the coal seam, in which the coal gasification process takes place. figure 1 shows the isotherms in pumping the oxidant into the formation, the temperature is $800 \mathrm{~K}$, and mass concentration of oxygen 0.1 .

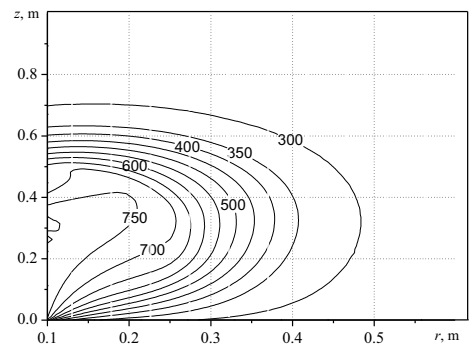

Fig. 1. The distribution of temperature in the coal when it overheats.

Increasing the mass concentration of the oxygen to 0.2 in vapor mixture injected into the coal seam, is leads to coal combustion. Even after reducing the injected oxidant temperature to $400 \mathrm{~K}$ it is combustion (fig. 2). 


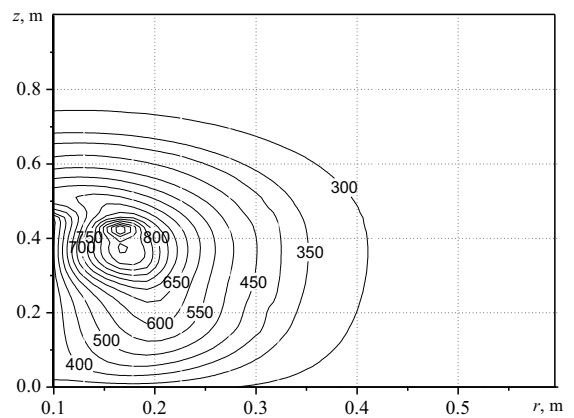

Fig. 2. The distribution of temperature in the coal seam after its ignition (Mass concentration of oxygen equal to 0.2 ).

Profiles of the volume fraction of coke for the same points in time are shown in figure 3.

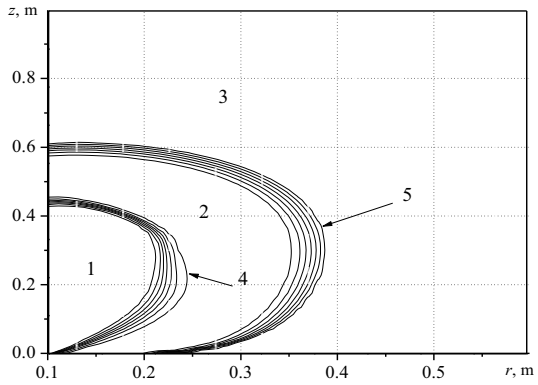

Fig. 3. Distribution of the volume fraction of coke upon heating the coal seam: 1 - an area in which the slag was; 2 - an area filled with char; 3 - unheated area filled with coal; 4 - boundary of coke oxidation; 5 - coal pyrolysis border.

Analyzing the graphs in figure 3, we conclude that formed three areas: 1 - where coal is burned down completely, it remained part of the non-combustible mineral; the area 2 , in which the coke oxidation occurs, the area 3 - coal seam, which has not yet come any chemical processes, since it is not warmed up. As shown by numerical calculations, the bulk of the resulting products of pyrolysis and combustion from the bottom base of the coal seam moves along processualnoe region 2 , moves along the boundary of pyrolysis, filtered in the outer tube and removed via the outer tube to the outside.

The bulk of the coal supplied to the layer of oxygen consumed in the areas 2 and 4 fig. 3 (oxidation products of pyrolysis), the rest of the volume of the test coal seam contains oxygen in small quantities. Formed in the oxidation of the pyrolysis coke and coal, carbon dioxide is moved together with the other gaseous components of the oxidation zone in the coke bed and enters the external tube wells. Therefore, in the coke focuses always the maximum concentration of all the resulting products of pyrolysis and combustion. In particular, in fig. 4 shows contours of carbon oxide. 


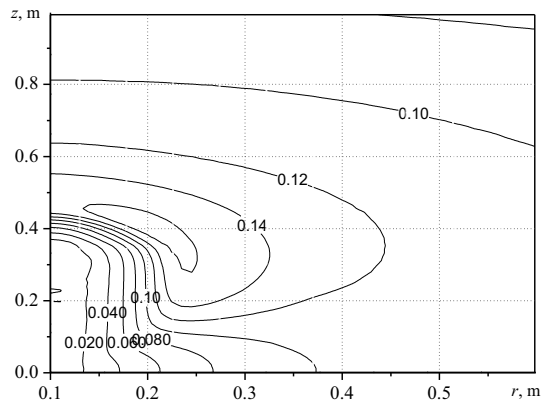

Fig. 4. Contours of the mass concentration of carbon monoxide.

Analyzing (fig. 4), the distribution of the mass concentration of carbon monoxide in gasification come to the conclusion that in the gas coming from the well, the mass concentration of $\mathrm{CO}$ is approximately equal to $0,12-0,14$. If to carry out the pyrolysis of coal in an inert atmosphere, the mass concentration of carbon monoxide formed during the pyrolysis of coal will be three times less.

The distribution of the mass concentration of carbon dioxide in a coal seam is shown in fig. 5. From this distribution we can conclude that, for given parameters of coal gasification in a coal seam, the content of carbon dioxide decreases sharply compared with coal pyrolysis in inert atmosphere (pyrolysis of coal in an inert atmosphere concentration of $\mathrm{CO}_{2}$ is three times more). The concentration of carbon dioxide can be further reduced by increasing the temperature of the gasification process.

From their analysis of the fields of mass concentrations of hydrogen and methane means that the concentration of these components is very small. During pyrolysis of coal in an inert environment mass concentration of hydrogen in twenty times, but methane is twenty five times higher. Such a strong decrease of the hydrogen concentration can be explained by its oxidation with the formation of water vapor, and methane - and carbon monoxide.

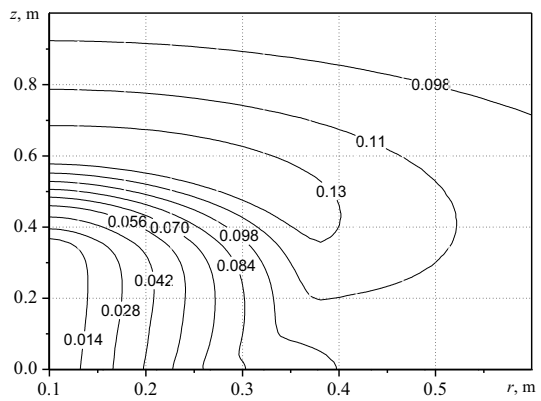

Fig. 5. Contours of the mass concentration of carbon dioxide.

This conclusion is confirmed by a significant increase in the mass concentration of water vapor in a coal seam (fig. 6). 


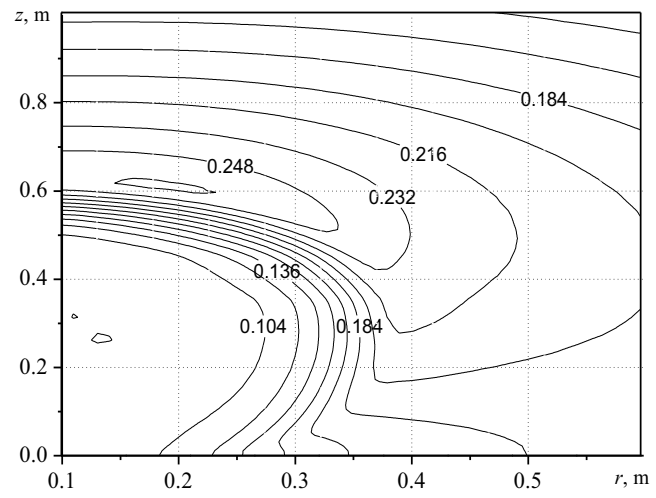

Fig. 6. The distribution of the mass concentration of water vapor.

In the vapor-air mixture supplied to the coal seam, the mass concentration of water vapor equal to 0.1 . Inside the reservoir, it increases more than doubled, partly due to the evaporation of moisture of the coal seam (asked the initial moisture content of the coal seam is equal to $5 \%$ ) and partly due to the fact that the reaction of hydrogen oxidation. It should be noted that the concentration of combustible gas in the gasification products is dependent on the concentration of water vapor, the gasification temperature and oxygen concentration in the vapor-air mixture supplied to the coal seam. In particular, if you increase the pressure drop, assuming it is equal to 2.103 PA, the velocity of the feed vaporair mixtures in the coal seam increases, and this changes the ratio of the concentrations of gaseous components at the outlet. In particular, the oxygen concentration at a given differential pressure increased slightly compared with the previous calculation. Ultimately, this led to the increase in the concentration of carbon monoxide in the exhaust from gasification gas. Profiles of the mass concentration of carbon monoxide is shown in fig. 7, from which it follows that in the outer tube receives a combustible mixture with the mass concentration of carbon monoxide $0,14-0,18$ (in the previous calculation it was equal to $0,12-0,14)$. The concentration of other components remained almost unchanged. When this differential pressure, the filtration velocity was doubled. Thus, the higher pressure drop in 2 times has led to the increase in the concentration of carbon monoxide and the volume of the resulting combustible mixture.

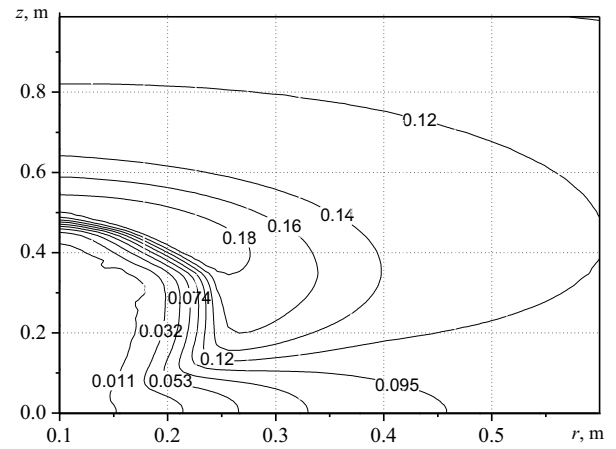

Fig. 7. The distribution of the mass concentration of carbon monoxide $\left(\mathrm{C}_{10}=0.1, \Delta \mathrm{P}=2 \cdot 10^{3} \mathrm{~Pa}\right)$.

In addition to the above results, calculations were carried out with an increased concentration of oxygen in air-steam mixture injected into the coal seam. Mass concentration of oxygen in the mixture was assumed equal to 0.15 and not 0.1 as in the 
previous calculations. The result is that the coal seam is increased, the oxygen concentration, which led to the increase in the concentration of carbon monoxide in the gasification products. In fig. 8 shows the volume distribution of the mass concentration of carbon monoxide while increasing by $50 \%$ the initial concentration of oxygen in air-steam mixture injected into the coal seam. Comparing fig. 8 and 4, we conclude that the increase in the initial oxygen concentration of $50 \%$ led to the increase in the concentration of carbon monoxide in the resulting gas mixture by about $50 \%$. The mass concentration of other components remained almost unchanged. Further increase in the concentration of oxygen in the vapor-air mixture supplied to the coal seam, leading to regime change, coal seam is ignited (there is an area of burning).

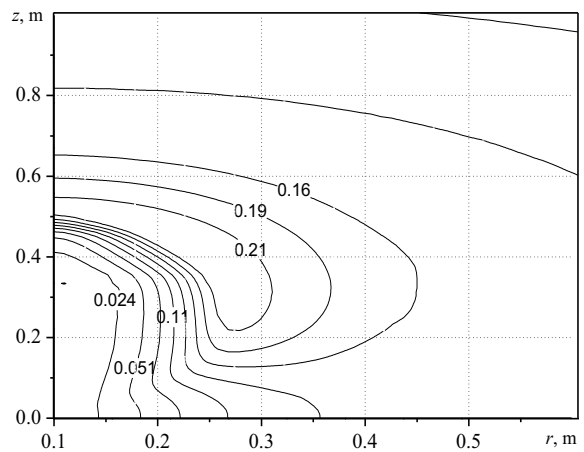

Fig. 8. The distribution of the mass concentration of carbon monoxide $\left(\mathrm{C}_{10}=0.15, \Delta \mathrm{P}=10^{3} \mathrm{~Pa}\right)$.

The temperature in this region rises to $1300 \mathrm{~K}$, even when the flow in the coal seam, after ignition, the relatively cool air-steam mixture $\left(T_{0}=400 \mathrm{~K}\right)$. The temperature rise in a coal seam led to the increase in the concentration of combustible gases. In fig. 9 shows the profiles of mass concentration of carbon monoxide. As follows from the analysis of this figure, the $\mathrm{CO}$ concentration at the outlet of the well was equal to $0.2 \div 0.3$, and in the area of maximum temperature is equal 0.45 .

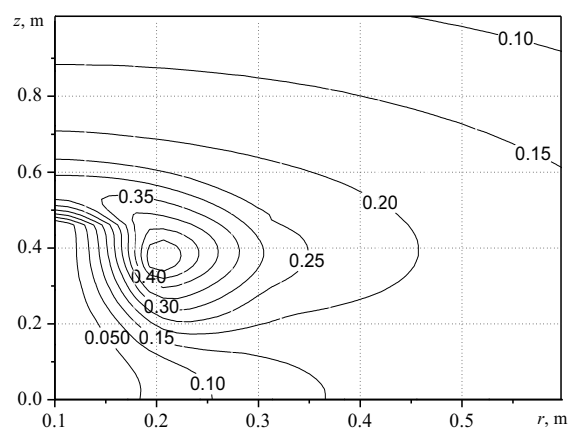

Fig. 9. The distribution of the mass concentration of carbon monoxide.

\section{Conclusions}

The results of numerical analysis give grounds to draw the following conclusions:

1. The mathematical model allows to predict the structure of products of gasification in a coal seam.

2. The supply and composition of the oxidant significantly affect the final yield of the main product of underground coal gasification. 
3. Large gradients, all the major required functions, the spatial movement area of the main reactions and the size of the object of study greatly complicate the process of numerical solution of the problem.

\section{References}

1. V.J. Arens, A.A. Vertman, G.H. Hcheyan, Vestnik RAEN [RANS reporter] 3 (2007) [in Russian]

2. A.Y. Zorya, E.V. Kreynin, S.N. Lazarenko, J. Coal Kuzbass. Interreg. Res. Prac. 4 (2009)

3. R.N. Kulesh, A.S. Mazanik, A.N. Subbotin, Bul. TPU 4 (2014)

4. Y.V. Vasychkov, B.M. Vorobiev, Invention patent No. 2100588 [in Russia]

5. G.V. Kuznetsov, A.N. Subbotin, Heat proc. in Tech. 9 (2010)

6. A. M. Grishin, V. I. Zinchenko, K. N. Efimov, A. N. Subbotin, A. S. Yakimov. Iteration-interpolation method and its application, (Publ. house TGU, Tomsk, 2004) 